\title{
Comparison of Coombs Gel Test with ELISA and Standard Tube Agglutination Tests Used in Serological Diagnosis of Brucellosis
}

\author{
Çiğdem Akalan Kuyumcu ${ }^{1}$ Serpil Erol², Rıza Adaleti³, Seniha Şenbayrak², Seçil Deniz${ }^{4}$, Orçun Barkay ${ }^{5}$ \\ 1 Department of Infectious Diseases and Clinical Microbiology, University of Health Sciences, Sancaktepe \\ Şehit Prof Dr ilhan Varank Training and Research Hospital, İstanbul, Turkey \\ 2 Department of Infectious Diseases and Clinical Microbiology, University of Health Sciences, Haydarpasa \\ Numune Training and Research Hospital, İstanbul, Turkey \\ 3 Department of Clinical Microbiology, University of Health Sciences, Haydarpasa Numune Training and Research \\ Hospital, İstanbul, Turkey \\ 4 Department of Infectious Diseases and Clinical Microbiology, Pamukkale University School of Medicine, Denizli, Turkey \\ 5 Department of Infectious Diseases and Clinical Microbiology, Erzincan Binali Yıldırım University, Mengücek Gazi \\ Training and Research Hospital, Erzincan, Turkey
}

\begin{abstract}
Objective: Serological tests are the most commonly used tests in the diagnosis of brucellosis; however, each serological test has some drawbacks. In this study, we aimed to determine the value of the Brucella Coombs gel test (BCGT) in the serological diagnosis of brucellosis in comparison with Standard tube agglutination (STA) and ELISA tests. Materials and Methods: The study included 42 patients who were considered to have brucellosis as a preliminary diagnosis. BCGT, Brucella-IgM/IgG ELISA, and STA tests were performed from serum samples of the patients. The correlation of the diagnostic tests was analyzed using Cohen's Kappa Analysis.

Results: Twenty-seven (64.2\%) of 42 patients were diagnosed with brucellosis according to their medical history and clinical and serological tests. The sensitivity and specificity of BCGT to diagnose brucellosis was $96.2 \%$, and 100\%, respectively. The sensitivity and specificity for the diagnosis of brucellosis $62.9 \%$ and $100 \%$ for STA, respectively; $33.3 \%$ and $66.6 \%$ for Brucella-IgM; and $66.6 \%$ and $100 \%$ for Brucella-IgG. BCGT was significantly correlated with STA $(\mathrm{k}=0.590)$ and Brucella-IgG $(\mathrm{k}=0.539)$

Conclusion: BCGT can be utilized as a simple and reliable test in the diagnosis of brucellosis with high sensitivity and specificity. Nevertheless, the sensitivity and specificity of BCGT should be demonstrated by comprehensive studies, including culture-confirmed cases and control groups.
\end{abstract}

Keywords: brusellozis, coombs gel test, serological diagnosis

\section{INTRODUCTION}

B rucellosis is a zoonotic infectious disease caused by Gram-negative bacteria of the genus Brucella, which is transmitted from animals to humans by direct and indirect pathways. Brucellosis can be confused with various infectious and non-infecti-
Corresponding Author: Çiğdem Akalan Kuyumcu

E-mail:

cigdemakalan@hotmail.com

Received: October 15, 2019

Accepted: December 21, 2019 Published: April 30, 2020

Suggested citation: Kuyumcu ÇA, Erol S, Adaleti R, Şenbayrak S, Deniz S, Barkay O. Comparison of Coombs Gel Test with ELISA and Standard Tube Agglutination Tests Used in Serological Diagnosis of Brucellosis. Infect Dis Clin Microbiol 2020; 1: 1-7.

DOI: $10.36519 / \mathrm{idcm} .2019 .0024$ 
ous diseases because of its nonspecific clinical signs and symptoms such as fever, sweating, fatigue, loss of appetite, headache, muscle and joint pain (1-3). The diagnosis is based on isolation of the microorganism from clinical samples, demonstration of antibody response in serological methods, or specific nucleic acid determination by molecular methods.

The definitive diagnosis of brucellosis requires isolation of the infectious agent from blood, bone marrow, cerebrospinal fluid samples, and from other clinical samples, including stool, wound, and joint fluid. However, the isolation rate of the bacteria may vary depending on the stage of the disease, previous antibiotic usage, the type and amount of the clinical sample, the type of bacteria, and the culture technique used. The positivity rate of blood cultures, therefore, varies between $15-90 \%$. Bone marrow cultures have been shown to be more sensitive and have a shorter isolation time than blood cultures (14). Especially in chronic cases, the probability of isolating the agent is low. Thus, serological methods are gaining popularity in the diagnosis of brucellosis (5).

The specificity and sensitivity of the serological tests used in the diagnosis may also be affected by the stage and the severity of the disease (1). Rose Bengal test (RBT), Standard Tube Agglutination Test (STA), Standard Tube Agglutination Test with Coombs (C-STA), Immunocapture Agglutination (ICA) test, ELISA and newly developed Brucella Coombs Gel test (BCGT) are frequently used in the serological diagnosis of brucellosis. BCGT is designed for the rapid detection of the antibodies against Brucella bacteria in human serum by the Coombs method. BCGT, which is carried out in wells containing gel matrix and Coombs antibody, allows performing STA and C-STA together, without the need for a long time for incubation. Beyond being a simple test in serological diagnosis, BCGT results demonstrate high consistency with the results of the C-STA test (6). In this study, we aimed to determine the diagnostic value of BCGT in comparison with STA and ELISA methods.

\section{MATERIALS AND METHODS}

Patients who admitted to Haydarpaşa Numune Training and Research Hospital, Department of
Infectious Diseases and Clinical Microbiology between February 2016 and February 2017 were included in the study. Patients who were under 18 years old or pregnant were excluded from the study. Detailed medical history, physical examination findings, and laboratory or radiology findings were recorded for each patient. Ten cc venous blood samples were drawn, centrifuged, and serum samples were stored at $-20^{\circ} \mathrm{C}$ until studying. Serum samples were dissolved and brought to room temperature before analysis. The STA test dilutions (Seromed, Istanbul) were made up 1/40 from 1/640 to titers, and $\geq 160$ titers were considered as positive. Brucella-IgM / IgG (VIRCELL, Santa Fe, GRANADA, SPAIN) antibody levels were measured by ELISA. All tests were carried out in accordance with the manufacturer's recommendations.

\section{Brucella Coombs Gel test}

This test takes place in microplate wells containing gel matrix and Coombs antibody. ODAK Brucella Coombs antigen (ODAK Brucella Coombs Gel test, Toprak Medical, Istanbul, Turkey) was added to the dilution wells on the plate, and this mixture was pipetted into the gel matrix microtubes. We applied dilution ranges of 1:40-1:5120 and considered $\geq 160$ titers as positive. Visual assessment was performed after centrifugation of the gel matrix for 20 minutes. The samples were accepted as negative if pink-coloured brucella antibody subsides at the bottom of microtubes or as positive if pink-coloured antibody floats over the gel. The test procedure took approximately two hours, including incubations and preparation. Both screening and dilution could be performed with this test (6).

\section{HIGHLIGHTS}

- BCGT is designed for the rapid detection of the antibodies against Brucella bacteria in human serum by the Coombs method.

- We found the sensitivity of BCGT as $96.2 \%$ and the specificity as $100 \%$.

- The main difference of this study than others is that the sensitivity and the specificity calculations are based not only on serological tests but also on clinical features. 
Study patients were categorized as acute $(<8$ weeks), subacute (8-52 weeks), and chronic (> 1 year) brucellosis according to the duration of their symptoms. Patients who had relapsing symptoms or signs of infection within 12 months after the completion of brucellosis treatment and increased levels of IgG class antibody or blood culture positivity were included in the relapse group. Patients completing treatment within the last six months were included in the previously treated group.

\section{Statistical analysis}

Statistical analyses were performed by the MedCalc Statistical Software version 12.7.7. Cohen Kappa analysis was used to examine the categorical variables. Kappa coefficient of $0 \leq k<0.20$ was accepted as no compliance, $0.20 \leq k<0.40$ was accepted as weak compliance, $0.40 \leq k<0.60$ was accepted as moderate compliance, $0.60 \leq k<0.80$ was accepted as high compliance, and $0.80 \leq \mathrm{k}<1.00$ was accepted as perfect compliance. The statistical significance was set as $<0.05$. Sensitivity and specificity calculations were performed using the following formulas:

Sensitivity $=$ True positive cases/All positive cases = True positive cases/ (True positive cases + False negative cases) $\mathrm{x} 100$,

Specificity = True negative cases $/$ All negative cases = True negative cases / (True negative cases + False positive cases) $\mathrm{x} 100$,

Positive predictive value $(\mathrm{PPV})=$ True positive cases / (True positive cases + False positive cases),

Negative predictive value (NPV) $=$ True negative cases / (True negative cases + False negative cases)

\section{RESULTS}

A total of 42 patients were enrolled in the study. The mean age was $47.2 \pm 15.9$, and $50 \%$ of them were male. Twenty-seven of these patients were diagnosed as brucellosis according to the medical history, physical examination findings and serological tests while the diagnosis of brucellosis was excluded in 15 patients.
Table 1. Serological tests results according to the clinical profiles of the patients.

\begin{tabular}{|c|c|c|c|c|}
\hline Patients & \multicolumn{4}{|c|}{ TESTS } \\
\hline $\begin{array}{l}\text { Acute Brucellosis } \\
\qquad(n=10)\end{array}$ & BCGT & STA & $\begin{array}{l}\text { ELISA- } \\
\text { IGM }\end{array}$ & $\begin{array}{l}\text { ELISA- } \\
\text { IGG }\end{array}$ \\
\hline 1. & + & + & - & + \\
\hline 2. & + & + & - & + \\
\hline 3. & + & + & + & - \\
\hline 4. & + & + & + & - \\
\hline 5. & + & + & - & - \\
\hline 6. & + & + & + & - \\
\hline 7. & + & + & + & + \\
\hline 8. & + & + & + & + \\
\hline 9. & + & - & - & + \\
\hline 10. & + & + & + & - \\
\hline \multicolumn{5}{|l|}{$\begin{array}{c}\text { Subacute } \\
\text { Brucellosis }(n=5)\end{array}$} \\
\hline 1. & + & + & - & + \\
\hline 2. & + & + & - & - \\
\hline 3. & + & + & + & + \\
\hline 4. & + & + & + & + \\
\hline 5. & + & + & - & - \\
\hline \multicolumn{5}{|l|}{$\begin{array}{l}\text { Chronic Brucellosis } \\
\qquad(n=6)\end{array}$} \\
\hline 1. & + & - & - & + \\
\hline 2. & - & - & - & + \\
\hline 3. & + & - & - & + \\
\hline 4. & + & - & - & + \\
\hline 5. & + & - & - & + \\
\hline 6. & + & - & - & + \\
\hline \multicolumn{5}{|l|}{$\begin{array}{l}\text { Relapse Brucellosis } \\
\qquad(n=4)\end{array}$} \\
\hline 1. & + & + & - & - \\
\hline 2. & + & + & - & + \\
\hline 3. & + & + & + & + \\
\hline 4. & + & - & - & + \\
\hline \multicolumn{5}{|l|}{$\begin{array}{l}\text { Previously Treated } \\
\qquad(n=2)\end{array}$} \\
\hline 1. & + & - & - & + \\
\hline 2. & + & - & - & - \\
\hline
\end{tabular}


Table 2. The number and rate (\%) of serological tests results according to the clinical profiles of the patients.

\begin{tabular}{|c|c|c|c|c|c|c|c|c|}
\hline \multirow{2}{*}{$\begin{array}{l}\text { Clinical } \\
\text { Profile }\end{array}$} & \multicolumn{2}{|c|}{ BCGT } & \multicolumn{2}{|c|}{ STA } & \multicolumn{2}{|c|}{ Brucella-IgM ELISA } & \multicolumn{2}{|c|}{ Brucella-IgG ELISA } \\
\hline & $\begin{array}{l}\text { Negative } \\
\text { (n) \% }\end{array}$ & $\begin{array}{r}\text { Positive } \\
\text { (n) \% }\end{array}$ & $\begin{array}{c}\text { Negative } \\
\text { (n) } \%\end{array}$ & $\begin{array}{c}\text { Positive } \\
\text { (n) } \%\end{array}$ & $\begin{array}{c}\text { Negative } \\
\text { (n) } \%\end{array}$ & $\begin{array}{c}\text { Positive } \\
\text { (n) } \%\end{array}$ & $\begin{array}{c}\text { Negative } \\
\text { (n) } \%\end{array}$ & $\begin{array}{c}\text { Positive } \\
\text { (n) } \%\end{array}$ \\
\hline Acute Brucellosis (10) & (0) 0.0 & (10) 100 & (1) 10 & (9) 90 & (4) 40 & (6) 60 & (5) 50 & (5) 50 \\
\hline Subacute Brucellosis (5) & (0) 0.0 & (5)100 & (0)0 & (5) 100 & (3) 60 & (2) 40 & (2) 40 & (3) 60 \\
\hline Chronic Brucellosis (6) & (1)16.6 & (5) 83.3 & (6)100 & (0)0.0 & (6)100 & (0)0.0 & (0)0.0 & (6) 100 \\
\hline Relapse Brucellosis (4) & (0)0.0 & (4)100 & (1) 25 & (3) 75 & (3) 75 & (1) 25 & (1) 25 & (3)75 \\
\hline Previously Treated (2) & (0)0.0 & (2) 100 & (2) 100 & (0) 0.0 & (2) 100 & (0)0.0 & (1) 50 & (1) 50 \\
\hline Non- brucellosis(15) & (15)100 & (0)0.0 & (15)100 & (0)0.0 & (10)66.6 & (5)33.3 & (15)100 & (0)0.0 \\
\hline Total & 16 & 26 & 25 & 17 & 28 & 14 & 24 & 18 \\
\hline
\end{tabular}

Thirteen (48.1\%) patients were female, and fourteen $(51.8 \%)$ were male out of 27 patients diagnosed as brucellosis. The mean age was $49.5 \pm 17.6$. When categorized according to the symptom duration, ten (37\%) patients were accepted as acute, five $(18.5 \%)$ as subacute, six (22.2\%) as chronic, and four $(14.8 \%)$ as relapsed brucellosis. Two (7.4\%) patients were accepted as previously treated. BCGT was positive in twenty-six (96.2\%) of the subjects, whereas STA was positive in 17 (62.9\%) subjects, and Brucella-IgM and had Brucella-IgG were positive in 9 (33.3\%), and 18 (66.6\%) subjects, respectively. One patient's BCGT, STA, and Brucella-IgM results were negative, while the Brucella-IgG result was positive. Patients' serological test results are presented in Table 1, and the number and rate (\%) of positive and negative serological test results are presented in Table 2.

Among the tests performed in the study, BCGT demonstrated the highest sensitivity (96.2\%) and specificity (100 \%) in addition to the highest PPV (100\%), and NPV (93\%). The Sensitivity, Specificity, PPV, and NPV of all tests used in this study are presented in Table 3.

Kappa analysis showed that BCGT was moderately but significantly correlated with STA and Brucella-IgG (Kappa: 0.590, and Kappa: 0.539, respective- ly). However, there were no significant correlations between BCGT and Brucella-IgM (Kappa: 0.029).

When STA was accepted as a reference test, and its positivity titers were taken as $\geq 160$, the sensitivity and the specificity of BCGT was found to be $100 \%$ and $64 \%$, respectively.

When we compared STA and BCGT titers, we found that the compliance rate was high in both at the levels of 1/160 and above. In two patients with BCGT positivity at $1 / 2560$ and $1 / 5120$ titers, STA was found negative. Brucellosis treatment of one patient was completed three weeks ago, and the other one was diagnosed as chronic brucellosis. A comparison of BCGT and STA results according to antibody titers is shown in Table 4.

\section{DISCUSSION}

Serological methods, most commonly STA, are frequently used in the diagnosis of brucellosis (4). Total brucella antibodies (IgG, IgM, and IgA) are determined by STA (7). However, false-negative results may be observed with STA due to several causes, including the prozone phenomenon, sampling at the early stages of the disease, and the presence of blocking antibodies. On the other hand, some of the gram-negative bacterial infections may cause 
Table 3. Rates of Sensitivity, Specificity, PPV and NPV of the tests used in this study (\%).

\begin{tabular}{|c|c|c|c|c|}
\hline Tests & Sensitivity & Specificity & PPV & NPV \\
\hline BCGT & 96.2 & 100 & 100 & 93 \\
\hline STA & 62.9 & 100 & 100 & 60 \\
\hline Brucella-IgM & 33.3 & 66.6 & 64 & 35 \\
\hline Brucella-IgG & 66.6 & 100 & 100 & 62.5 \\
\hline
\end{tabular}

Table 4. A comparison of BCGT and STA results according to antibody titers.

\begin{tabular}{|c|c|c|c|c|c|c|c|}
\hline \multirow[b]{2}{*}{$\begin{array}{l}\text { BCGT } \\
\text { (antibody titers) }\end{array}$} & \multicolumn{7}{|c|}{ STA (antibody titers) } \\
\hline & $\begin{array}{c}0 \\
(n)\end{array}$ & $\begin{array}{l}1 / 40 \\
(n)\end{array}$ & $\begin{array}{c}1 / 80 \\
(n)\end{array}$ & $\begin{array}{c}1 / 160 \\
(n)\end{array}$ & $\begin{array}{c}1 / 320 \\
\text { (n) }\end{array}$ & $\begin{array}{l}\geq 1 / 640 \\
\text { (n) }\end{array}$ & $\begin{array}{c}\text { Total } \\
\text { (n) }\end{array}$ \\
\hline$O(n)$ & 12 & 2 & 1 & 0 & 0 & 0 & 15 \\
\hline $1 / 40(n)$ & 0 & 0 & 0 & 0 & 0 & 0 & 0 \\
\hline $1 / 80(n)$ & 1 & 0 & 0 & 0 & 0 & 0 & 1 \\
\hline $1 / 160(n)$ & 4 & 1 & 1 & 1 & 0 & 0 & 7 \\
\hline $1 / 320(n)$ & 1 & 0 & 0 & 2 & 0 & 1 & 4 \\
\hline $1 / 640(n)$ & 0 & 0 & 0 & 2 & 2 & 0 & 4 \\
\hline $1 / 1280(n)$ & 0 & 0 & 0 & 0 & 2 & 2 & 4 \\
\hline $1 / 2560(n)$ & 1 & 0 & 0 & 1 & 0 & 2 & 4 \\
\hline $1 / 5120(n)$ & 1 & 0 & 0 & 0 & 0 & 2 & 3 \\
\hline Total(n) & 20 & 3 & 2 & 6 & 4 & 7 & 42 \\
\hline
\end{tabular}

false-positive results (8). If false negativity is considered, C-STA is used as an extension of STA to determine further the presence of blocker or non-agglutinated immunoglobulins (7). Recently, BCGT, a much more practical method, has been developed. This test, which is performed in wells containing gel matrix and Coombs antibody, allows STA and C-STA testing at the same time. While $24-48 \mathrm{hr}$ incubation is required in STA and C-STA, BCGT results can be obtained in less than 2 hours without incubation $(6,9)$. However, evidence regarding the implementation of BCGT in the diagnosis of the brucellosis is limited due to the novelty of this test. In a recent study by Turk Dagi et al., the sensitivity and specificity of BCGT in the diagnosis of the brucellosis was $94.6 \%$, and $100 \%$, respectively, which was significantly higher than that of the C-STA (10). In another study conducted by İrvem and colleagues, BCGT was found to have excellent compatibility with ICA and C-STA test (11). Among these tests, the ICA test, which is practical and fast, is applied with similar principles to BCGT. The most important advantage of BCGT over the ICA is that the 24-hour incubation time of ICA is less than 2 hours in BCGT, and results 
are taken in a shorter time with BCGT. In a study, of which the ICA was taken as a reference test, the sensitivity of STA, ICA, and BCGT were reported as $71.4 \%, 100 \%$, and $100 \%$, respectively, and the specificity was reported $100 \%$ for all three tests (12). In a study by Turhanoglu et al., the sensitivity and specificity of STA were $90.3 \%, 100 \%$ respectively, whereas the sensitivity and specificity of BCGT were $97.5 \%$, $100 \%$, respectively (13). In another study by Hancl et al., the sensitivity and specificity of BCGT were $100 \%$ and $82.2 \%$, and the sensitivity and specificity STA were $53.4 \%$, and $100 \%$, respectively (14). In our study, we found that the sensitivity of BCGT as $96.2 \%$ and specificity as $100 \%$, which is highly consistent with the results of the previous studies. We also found that the sensitivity of STA as $62.9 \%$ and its specificity as $100 \%$. Our findings demonstrate a moderate correlation between STA and BCGT. The correlation shown between STA and BCGT is also consistent with the results of the previous research (15).

ELISA is the second most frequently used serological method to detect Brucella-IgM and IgG antibodies (16). Although there is enough data comparing ELISA and STA in the diagnosis of brucellosis, there are currently very few studies comparing the efficacy of ELISA and BCGT in brucellosis. The present study is one of the first studies comparing the diagnostic role of ELISA and BCGT in patients with brucellosis. Ozdemir et al. indicated that the sensitivity of ELISA IgM and IgG's were $73.7 \%$ and $72.2 \%$ in brucellosis (17). We determined the sensitivity and specificity of IgM as $33.3 \%$, and $66.6 \%$, and the sensitivity and specificity of IgG as $66.6 \%, 100 \%$, respectively. Compared to ELISA, the sensitivity and specificity of the BCGT to diagnose the brucellosis were significantly higher in our study. Moreover, no concordance was observed between BCGT and Brucella-IgM results, although there was a moderate correlation between BCGT and Brucella-IgG results. Previous data indicate that the ELISA test shows similar results with STA in the acute period, but is more sensitive in chronic and healed cases (18). In our study, we observed only one patient with chronic brucellosis who was diagnosed with IgG positivity. In acute cases, IgM can be found increased alone or with IgA and IgG. In chronic cases, IgG can be found increased alone or with IgA. In acute cases of the present study, while the sensitivity of IgM was $80 \%$, IgG's sensitivity was
90-100 \%. In subacute cases, the performance of IgM decreases while IgG provides better results than IgM; however, in some cases, both IgM and IgG may be negative (19). In our study, nine of 26 patients who were positive for BCGT were IgM positive, and seventeen of them were IgG positive.

BCGT, STA, and Brucella-IgM were negative in one patient, while Brucella-IgG was positive. This patient, who was finally diagnosed as chronic brucellosis, was living in the endemic region and had complaints of sweating, arthralgia, headache, and lumbar spondylodiscitis for more than one year. The main difference of our study than others is that the sensitivity and specificity calculations are based not only on serological tests but also on clinical features.

Relapses may occur in 5-40\% of acute brucellosis cases, and cultures may also be negative in these cases. Clinical findings and serological tests are of great importance in these patients (19). In one study, positivity rates of C-STA with brucella IgG, IgA, STA were $83 \%, 58 \%, 25 \%$, respectively; and brucella IgM was negative in such patients with brucellosis. ELISA IgG, IgA, and Coombs accumulating titers are good indicators of relapse, while IgM is of poor value (20). In our study, BCGT, STA, Brucella-IgM and IgG positivity rates were $100 \%, 75 \%, 25 \%$ and $75 \%$, respectively, in patients with relapse brucellosis.

The criteria used for the diagnosis of brucellosis and clinical features of the study groups vary in previous studies. This variation can somewhat explain the differences in our results and previous evidence.

In microbiology laboratories, in addition to the STA test, at least one agglutination test or ELISA Brucella-IgM/IgG study is recommended to improve the reliability of the results (7). The most important limitation of our study was that the limited number of cases and culture positivity rates affecting the comparability.

In conclusion, the results of the present study show that BCGT may be useful in the diagnosis of brucellosis due to its high sensitivity and specificity. However, as a new test, BCGT has to be studied further with culture-confirmed cases and control groups, so that it can take part in routine diagnostic laboratories. 
Informed Consent: Written consent was obtained from the patient.

Ethical Approval: The University of Health Sciences, Haydarpasa Numune Training and Research Hospital Clinical Research Ethics Committee, Turkey, approved the study with the decision number of 2016/05.

Peer-review: Externally peer-reviewed

Author Contributions: Concept - Ç.A.K, S.E; Design - Ç.A.K, S.E;
Supervision - Ç.A.K, S.E, S.Ş; Funding - Ç.A.K, R.A; Materials - Ç.A.K, R.A; Data Collection and/or Processing - Ç.A.K, S.D; Analysis and/or Interpretation - ALL; Literature Review ALL; Writer - Ç.A.K,S.E, S.Ş, O.B; Critical Reviews - S.E., S.Ş.

Conflict of Interest: The authors have no conflict of interest to declare.

Financial Disclosure: The authors declared that this study has received no financial support.

\section{REFERENCES}

1 Doğanay M, Alp Meşe E. Bruselloz. Willke Topçu A, Söyletir G, Doğanay M, editors. Enfeksiyon hastallklan ve mikrobiyolojisi. 3th ed. Ankara: Nobel Tip Kitabevleri; 2008.p.897-909.

2 Sümerkan B. Brucella Türleri. Willke Topçu A, Söyletir G, Doğanay M, editors. Enfeksiyon hastallklan ve mikrobiyolojisi. 3th ed. Ankara: Nobel Tip Kitabevleri; 2008.p.2237-43.

3 Hume R, Snyder JW. Biyoterörizm etkenlerinin laboratuvar tanısı. Murray PR, Baron EJ, Landry ML, Jorgensen JH, Pfaller MA. Translation editor: Başustaoğlu A. Klinik mikrobiyoloji 9th ed. Ankara: Atlas Kitapçllık Tic. Ltd. şti; 2009.p.107-17.

4 Gül HC, Erdem H. Brucella species. Mandel GL, Bennet JE, Dolin $\mathrm{R}$, editors. Principles and Practice of Infectious Disease. 8th ed. Vol 2, 2016. p.2584-88

5 Ulusal Mikrobiyoloji Standartlan, Mikrobiyolojik Tanımlama / Bakteriyoloji, Sürüm: 1.1 / B-MT-19 / Bruselloz 01.01.2015:1-27.

6 http://www.toprakmedikal.com/urunler.aspx?id=4, ODAK Brucella Coombs jel test. Date of access: 20.09.2016.

7 Araj GF. Update on laboratory diagnosis of human brucellosis. Int J Antimicrob Agents 2010; 36: 12-17.

8 Pappas G, Akritidis N, Bosilkovski M, Tsianos E. Brucellosis. N Engl J Med 2005; 352: 2325-36.

9 Kocagöz T. Türkiye'de mikrobiyoloji alanında bilime dayalı üretim. ANKEM Derg 2014; 28: 115-19.

10 Türk Dağı H, Fındık D. Bruselloz tanısında yeni bir yöntem: Brucella Coombs jel test. Genel Tip Derg 2016; 26: 19-22.

11 İvem A, Yücel FM, Aksaray S, Bor E. Brusellozun serolojik tanısında yeni ve hızlı bir yöntem olan Brucella Coombs jel testi ile diğer yöntemlerin karşılaştırılması. Mikrobiyol Bul 2015; 49: 181-87.
12 Kalem F, Ergün AG, Durmaz S, Doğan M, Ertuğrul Ö, Gündem S. Comparison of a new and rapid method: Brucella Coombs jel test with other diagnostic tests. J Clin Lab Anal 2016; 30: 756-59.

13 Turhanoğlu NM, Gür VD. The comparison of Brucella jel agglutination test with other Brucella tests. Dicle Med J 2015; 42: 422-26.

14 Hanci H, Igan H, Uyanik MH. Evaluation of a new and rapid serologic test for detecting brucellosis: Brucella Coombs jel test. Pak J Biol Sci 2017; 20: 108-12.

15 Koroglu M, Akkaya AO, Demiray T, Erkorkmaz U, Ozbek A, Altindis M. Comparative evaluation of the Brucella Coombs jel test in laboratory diagnosis of human brucellosis. J Biotechnol 2016; 30: 970-5

16 Kandemir Ö. Bruselloz. Türkiye Klinikleri. J Inf Dis-Special Topics 2015; 8: 19.

17 Özdemir M, Feyzioglu B, Kurtoglu MG, Dogan M, Dagi HT, Yuksekkaya S, et al. A comparison of immuncapture agglutination and ELISA methods in serological diagnosis of brucellosis. Int J Med Sci 2011; 8: 428-32.

18 Fadeel MA, Hoffmaster AR, Shi J, Pimentel G, Stoddard RA. Comparison of four commercial IgM and IgG ELISA kits for diagnosing brucellosis. J Med Microbiol 2011; 60: 1767-73.

19 Alışkan H. Kültür ve serolojik yöntemlerin insan brusellozu tanısındaki değeri. Mikrobiyol Bul 2008; 42: 185-95.

20 Pellicer T, Ariza J, Foz A, Pallares R, Gudiol F. Specific antibodies detected during relapse of human brucellosis. J Infect Dis 1988; 157: 918-24. 